\title{
Comparison of Fuel Economy between Hydraulic Hybrids and Hybrid Electric Vehicles
}

\author{
Chi-Jui Huang*, Ming-Siang Du, Go-Long Tsai \\ Graduate institute of Mechanical and Electrical Engineering, National Taipei University of Technology, Taiwan
}

Copyright (C) 2015 by authors, all rights reserved. Authors agree that this article remains permanently open access under the terms of the Creative Commons Attribution License 4.0 International License

\begin{abstract}
Due to the conventional vehicles produce a lot of pollution and fuel consumption in driving. So the purpose of this study was to effectively improve emission and energy consumption, and kept the original vehicles in the better performance. Although pure electric vehicle had the good performance and low pollution features, the vehicle was limited by the distance, and the batteries were very expensive comparing to the conventional vehicle. The hybrid vehicles could achieve energy-saving purposes, but the prices of vehicles and the replaced batteries were still expensive than conventional vehicles. Hydraulic hybrid vehicles engines need to be accelerated with other dynamic alternate during work. And as the hydraulic accumulators exhausted, the accumulator would return to traditional mode. In the meantime, the engines will take the advantage of dynamic brake and pump energy recycles, and therefore fuel consumption and energy recovery function could be reached. In this study applied the feed-back simulation to establish hydraulic hybrid vehicle and hybrid electric vehicle models, and the NEDC (New European Driving cycle) was applied and simulated in this energy state. The simulation results showed the hydraulic hybrid vehicles had $56.7 \%$ better fuel economy efficiency than hybrid electric vehicles, this was the tremendous contribution on this study.
\end{abstract}

Keywords Hydraulic Hybrid Vehicle, Hybrid Electric Vehicle, Hydraulic Pump/Motor, Hydraulic Accumulators, Feed-back Simulation

\section{Introduction}

General speaking, conventional manual or automatic transmission allowed the engine speed within a certain range, and the final drive output speed and torque to meet the driver's needs. The biggest drawback was the need to rely on the transmission to shift gear when the gearbox changes gear, the engine speed will obviously feel increased or decreased, and feeling frustrated by the shift time is generated at this moment. But stepless transmission (CVT) does not produce the shift feeling frustrated during a shift, so that passengers could ride more comfortable vehicles. The advantage for the stepless gearbox allows the engine power was not lost, and always maintained the most efficient in the peak region, but also allowed the engine speed maintained at a certain area, stepless gearbox was easy maintenance due to simple structure. But the disadvantage was the engine torque to the stepless transmission processing, the belt or chain was limited strength, could not able to bear much friction.

However Hydraulic transmission (HST) was widely used in the machine tool industry, construction machinery, construction machinery, vehicles, air transport [1], and its advantages could be listed as following:

(1) Drive smoothly: the hydraulic drive unit, since the hydraulic oil shrinkage was very small, under normal pressure could be treated as incompressible, which was relied on a continuous flow of hydraulic oil carried drive, and the tubing hydraulic cushioning device can also be designed and set in so that the transmission buffer was stable.

(2) Light, small size: hydraulic transmission compared with the mechanical, electrical and other transmission mode in which the output power at the same conditions, the volume and quality could be reduce, so the inertia was small and the transmission reaction would be quick.

(3) Carrying capacity: the hydraulic drive was easy to get a lot of power and torque.

(4) Easy to implement variable speed: In hydraulic transmission, regulate the flow of liquid could achieve stepless speed range up to $2000: 1$, and easily access to a very low speed.

From the transmission of the view, the hydraulic drive system could achieve similar variable speed function. The principle was to use the hydraulic pump to the engine mechanical energy into hydraulic energy, through a change in the hydraulic energy transfer energy through the various control valves, the transmission line, and finally through the hydraulic motors. The high pressure hydraulic energy would transfer to mechanical energy and achieve driving. Wherein to achieve stepless speed change function, the simple way 
was changing the hydraulic motor or opening degree of hydraulic pump of this system to provide a continuous and wide variable reduction ratio, but usually a higher or lesser degree of opening of the pressure of the hydraulic motor / pump would get poor efficiency.

The Origin of the hydraulic hybrid power system could be dating back to 1972, Dunn and Wojciechowski [2] in the energy conversion engineering workshop in the post, the study by the Welfare Adams company VW 311 vehicle engines to run fly wheel, simulated the entire vehicle energy, the device has a 5 gallon pressure accumulator, $4.8 \mathrm{in}^{3} / \mathrm{rev}$ variable volume pump and other hydraulic components, hydraulic pump through a simulated vehicle deceleration recovered energy stored in the accumulator and the subsequent release for fly wheel use. From thus research the use of a hydraulic system was beginning at that way, you can recycle most of the original vehicle braking energy. The subsequent scholars continuously explore, 1992 Pourmovahed, Beachley and Fronczak [3] applied the components of hydraulic hybrid power system to conduct simulated match combinations by experiment that flywheel energy recovery model could reach between $61 \%$ to $89 \%$ recovery energy.

Concerning about the hydraulic power products applied on the vehicle that could be pointed that the 1982 Parker Hannifin Corporation [4] and joint architecture of hybrid systems Cumulo Brake Drive proposed a cascaded architecture hydraulic in 1991 of hybrid systems Cumulo Hydrostatic Drive. In the world the companies promote the hydraulic hybrid power systems and their products are: Bosch Rexroth's Hydrostatic Regenerative Braking System (referred to as HRB), Eaton's Hydraulic Launch Assist (referred to as HLA), Parker Hannifin's RunWise Advanced Series Hybrid Drive (referred RunWise) [5-7] and so on.

\section{Modeling}

This section applied Mat lab / Simulink software to create feedback-in hybrid vehicles (Hybrid Electric Vehicle, HEV) with a hydraulic hybrid vehicles (Hydraulic Hybrid Vehicle, HHV), and the model was shown in Figure 1 and Figure 2.
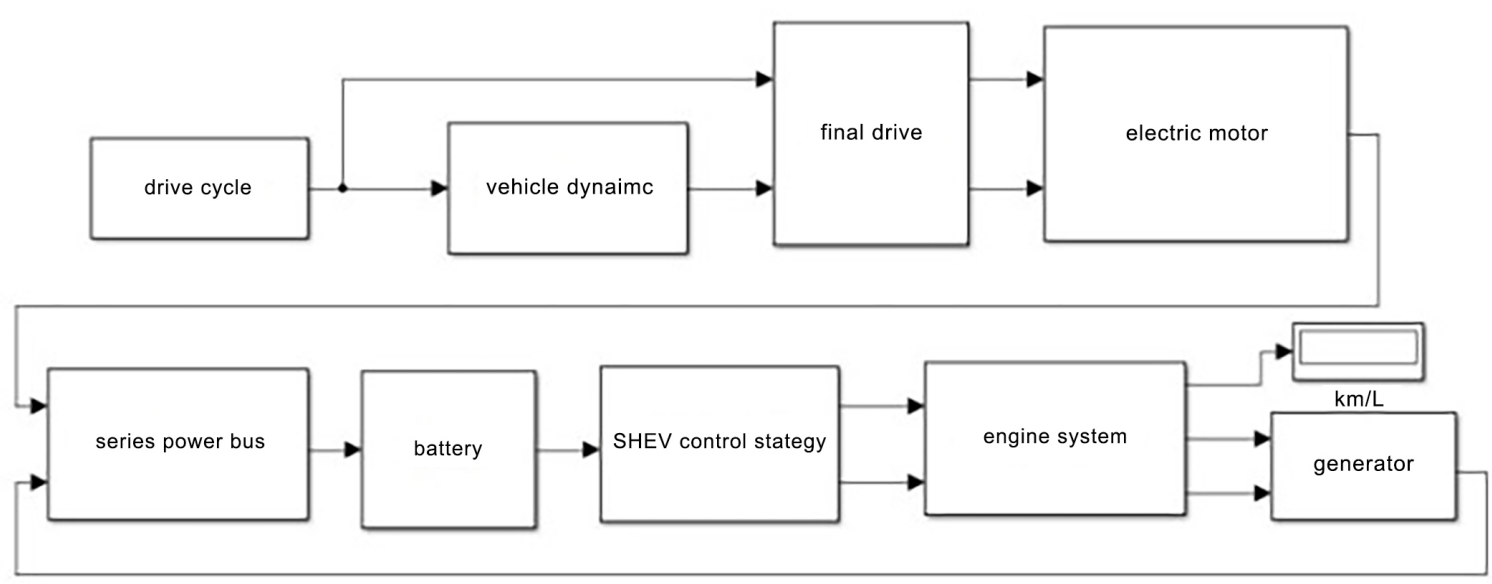

Figure 1. Simulation for hybrid vehicle power system

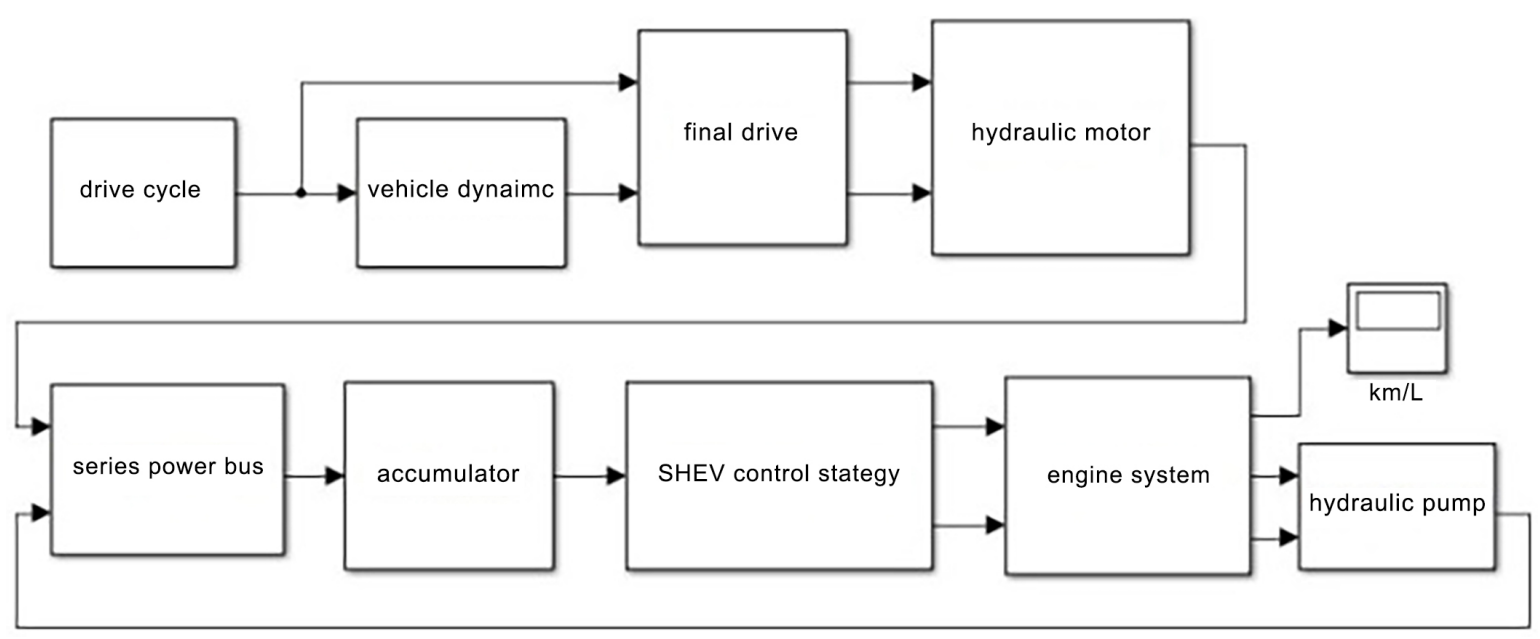

Figure 2. Each hydraulic system simulation of hybrid vehicle 


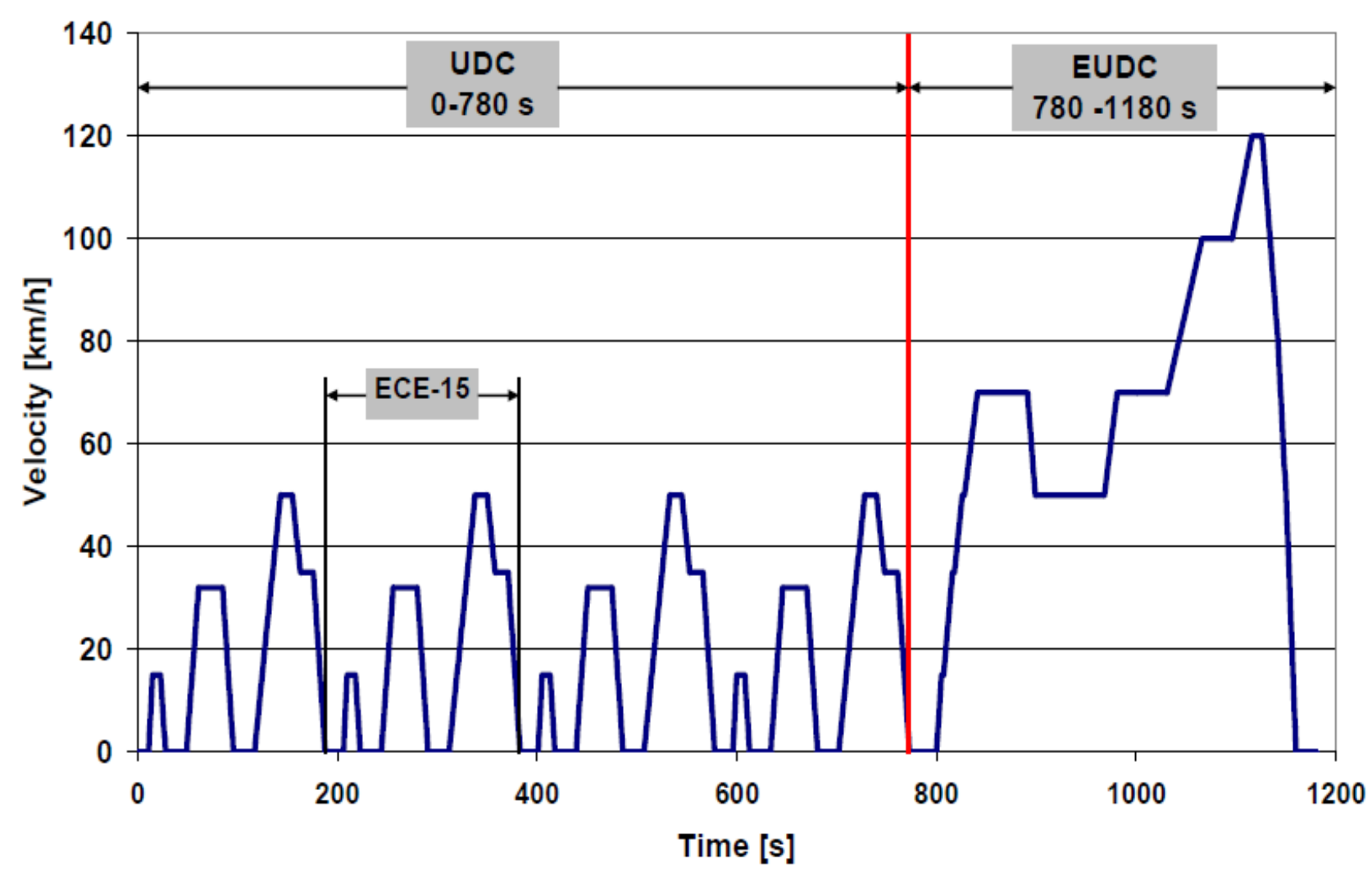

Figure 3. The new European driving cycle [8]

\subsection{Driving Cycle Model}

The study was adopting the new European standard test driving cycle (New Europeon Driving Cycle, NEDC)which was shown in Figure 3, the total driving cycle time was 1180 seconds, from the urban driving cycle (Urban Driving Cycle, UDC) and highway driving cycle (Extra-Urban Driving Cycle, EUDC), which 780 seconds belonged to the urban driving cycle, and the top speed was $50 \mathrm{~km} / \mathrm{hr}$, and 400 seconds belonged to highway driving cycle. The maximum speed was $120 \mathrm{~km} / \mathrm{hr}$.

\subsection{Vehicle Dynamics Model}

In order to deal with the dynamics model, the simulation of the resistance comprised a rolling resistance, air resistance, acceleration resistance and the climbing resistance. The speed could be

Obtained from the NEDC driving cycle, and after proceeding from this cycle the required torque value could be obtained either.

\subsubsection{Rolling resistance}

As driving a vehicle, the tire was rolling on the wheel. The ground contact area would interact both radial and lateral force of the tire. The ground reaction on tires, which must be accompanied by a deformation energy loss, the cause of energy loss was as the rolling resistance of the wheel is rotated, and the following formula could be expressed as

$$
R_{r}=\mu_{r} \cdot W
$$

$R_{r} \quad$ Rolling resistance

$\mu_{r} \quad$ Rolling resistance coefficient

$W \quad$ Vehicle Gross Weight.

\subsubsection{Air resistance}

When the vehicle was traveling, the air pressure acting on the front of the vehicle body was generated, known as air resistance. At low speeds, little effect of air resistance. However, at high speed, because the air resistance was proportional to the square of the speed, so the air resistance was represented as the following formula.

$$
R_{a}=C_{D} \cdot \frac{\rho}{2} \cdot A_{f} \cdot\left(v-v_{w}\right)^{2}
$$

$R_{a} \quad$ Air resistance

$C_{D} \quad$ Air resistance coefficient

$\rho$ Air density

$A_{f}$ Orthographic projection area of the vehicle

$v$ Vehicle velocity

$v_{w}$ Air velocity

\subsubsection{Climbing resistance}

As the vehicle was traveling uphill, climbing resistance was arising from the opposite direction which would affect the weight of the vehicle itself. When the vehicle was traveling downhill, the vehicle driving force became the anti-resistance, and could be expressed as the following formula: 


$$
R_{c}=W \sin (\theta)
$$

$R_{c} \quad$ Climbing resistance

$\theta \quad$ Slope angle

\subsubsection{Acceleration $r$ resistance}

In addition to the traveling state of the vehicle on the highway at fixed speeds, most vehicles were at acceleration and deceleration condition. General speaking, the vehicle needed more power than the steady running. The vehicle should entering the acceleration mode to conquer inertial resistance of rotating engine and components, clutch, transmission, drive shafts an, tires and so on, this resistance is called acceleration resistance, the formula could be expressed as following:

$$
R_{s}=\left(W+W_{f}\right) \cdot a / g
$$

$R_{S} \quad$ Acceleration resistance

$W_{f}$ The same amount of weight rotating element

$\alpha$ Acceleration

$G$ Gravity.

\subsection{Engine MODEL}

In this study the main driving force loaded on the vehicle was 1 liter of $41 \mathrm{kw}$ petrol engine, the engine speed and engine torque could be checked up the table, and therefore the braking ratio of fuel consumption (brake specific fuel consumption, bsfc) could be obtained, and the fuel consumption of the vehicle could be calculated and shown in Figure 4.

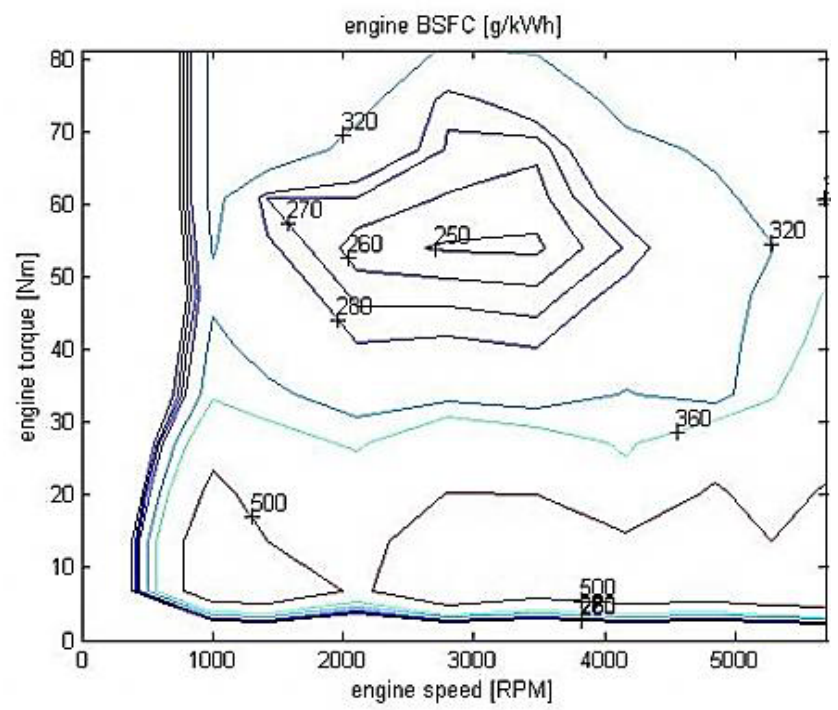

Figure 4. Contour map of 1 liter petrol engine BSFC

\subsection{Energy Storage Element Model}

For energy storage component parts, comparing hydraulic accumulator power density with the lithium-ion batteries and lead-acid batteries, nickel hydrogen batteries is the highest. But from" the energy density" point of view, the energy density of the hydraulic accumulator was the lowest, which could be shown in Figure 5.

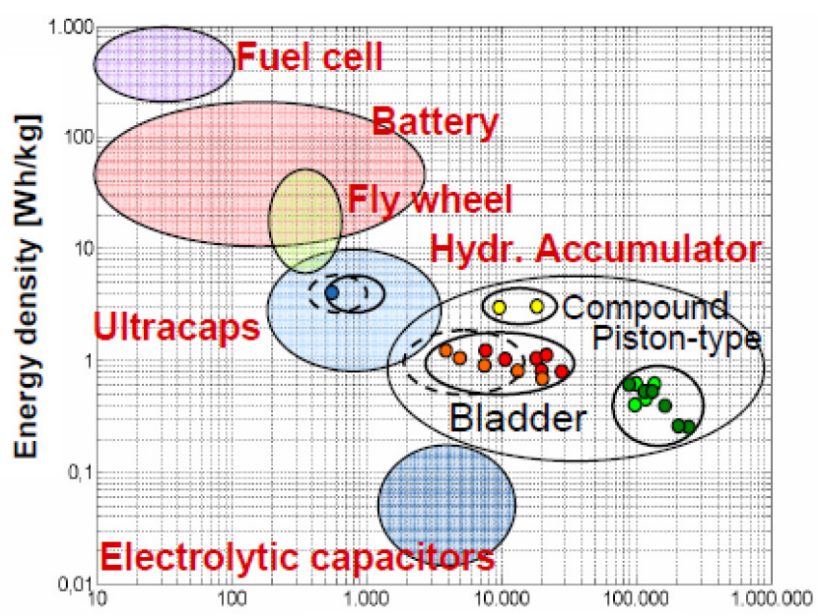

Figure 5. The ratio of energy density and power density for accumulator and battery [9]

\subsubsection{Battery model}

The nickel-metal hydride battery was used in this study, the voltage was $330 \mathrm{~V}$, and power capacity was $4 \mathrm{Ah}$, and therefore the total electric energy was $1.32 \mathrm{kWh}$. To create a simple battery model RC circuit diagram which was shown in Figure 6 and the correlation equation could be written as

$$
V_{t}=V_{o c}-I_{b a t} \cdot R_{\text {int }}
$$

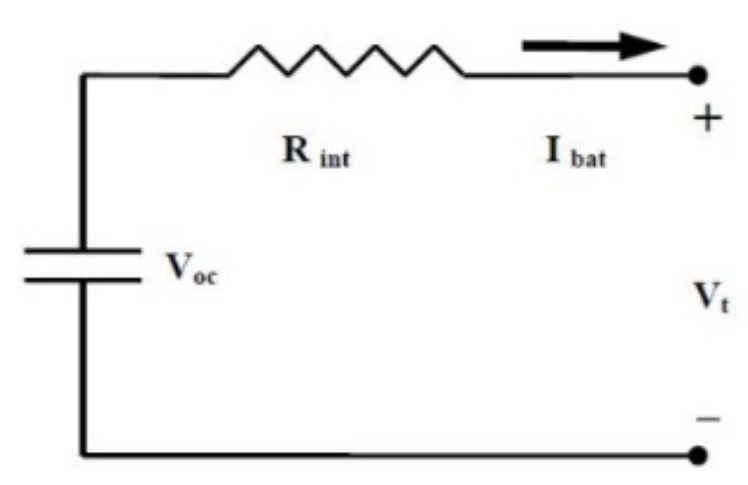

Figure 6. Simple RC circuit diagram

$V_{o c} \quad$ Open circuit voltage

$R_{\text {int }}$ Internal resistance of the battery

$V_{t} \quad$ Battery terminal voltage

$I_{b a t}$ Output current of the battery

Usually, terminal voltage and current could be measured, and it could be calculated by the following formula:

$$
P_{b a t}=I_{b a t} \cdot V_{o c}
$$

Then put (5) into (6) and the (7) could be obtained

$$
I_{\text {bat }}=\frac{V_{t}-\left(V_{t}{ }^{2}-4 \cdot R_{\text {int }} \cdot P_{\text {bat }}\right)^{0.5}}{2 R_{\text {int }}}
$$

Battery SOC was so called Ampere-Hours, and due to SOC would change with the charge and discharge currents, it 
could be obtained from the following formula:

$$
S O C=S O C_{i n t}-\frac{\int_{0}^{t} I_{b a t} d t}{A h}
$$

\subsubsection{Accumulator model}

Accumulator specifications were applied balloon-type accumulator with a capacity of $22 \mathrm{~L}$, working pressure was 150 bars to 420 bars. To create a model of the accumulator was shown in Figure 7. And the varied process was according to the laws of thermodynamics, the gas expansion and the actual compression processes, the relationship between pressure and volume could be expressed as the following equations:

$$
\begin{gathered}
P V^{n}=\text { Constant } \\
P_{0} V_{0}{ }^{n}=P_{1} V_{1}{ }^{n}=P_{2} V_{2}{ }^{n}=\text { Constant } \\
V_{1}=\left(\frac{P_{2}}{P_{1}}\right)^{\frac{1}{n}} V_{2}
\end{gathered}
$$

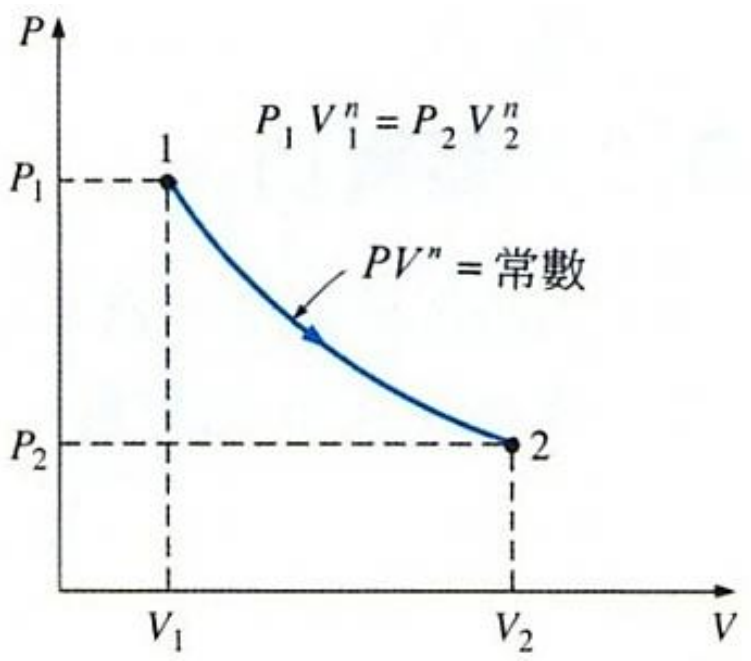

Figure 7. The accumulator $\mathrm{P}-\mathrm{V}$ changing processes [11]

Hydraulic hybrid hydraulic accumulator brake kinetic energy recovery function was mainly assumed that the vehicle traveling speed $v_{1}$ to $v_{2}$ deceleration energy generated $\Delta \mathrm{E}_{\mathrm{a}}$; the decrease in the kinetic energy could be calculated as the following equation:

$$
\Delta E_{a}=\frac{1}{2} M\left(v_{1}^{2}-v_{2}^{2}\right)
$$

The maximum volume change could be stored in the accumulator was calculated by the following formula:

$$
\Delta V_{a}=V_{1}\left[1-\left(\frac{P_{1}}{P_{2}}\right)^{\frac{1}{n}}\right]
$$

Typically the SOC of the accumulator represented by the size of the volume, as the result of SOC would create a volumetric flow rate changes, so the accumulator pressure was obtained by using the following formula's SOC:

$$
S O C=S O C_{i n t}-\frac{\int_{0}^{t} Q d t}{V_{f}}
$$

\subsection{Driving Element Model}

For parts of the drive elements, the hydraulic motor / pump / generator, a hydraulic motor / pump had a higher power density $(\mathrm{kW} / \mathrm{kg})$. The greater power density of the vehicle acceleration and deceleration, the greater ability of the electric motor which was s shown in Figure 8.

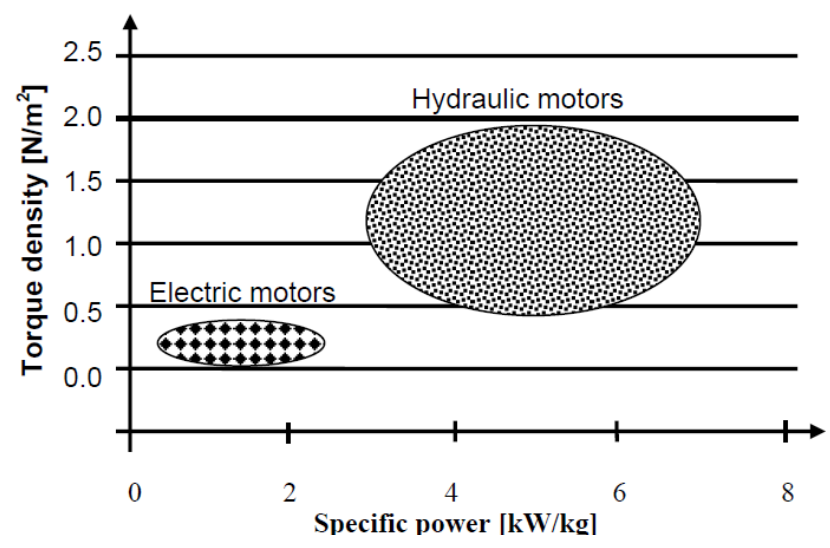

Figure 8. Hydraulic motor / pump and electric motor / generator power density [12]

\subsubsection{Electric motor model}

The $75 \mathrm{~kW}$ electric permanent magnet motor was used in this study that was a DC motor with a low-speed torque. According to the reverse-type manner, the torque and speed have been calculated and the motor efficiency curve was shown in Figure 9 through the previously stored.

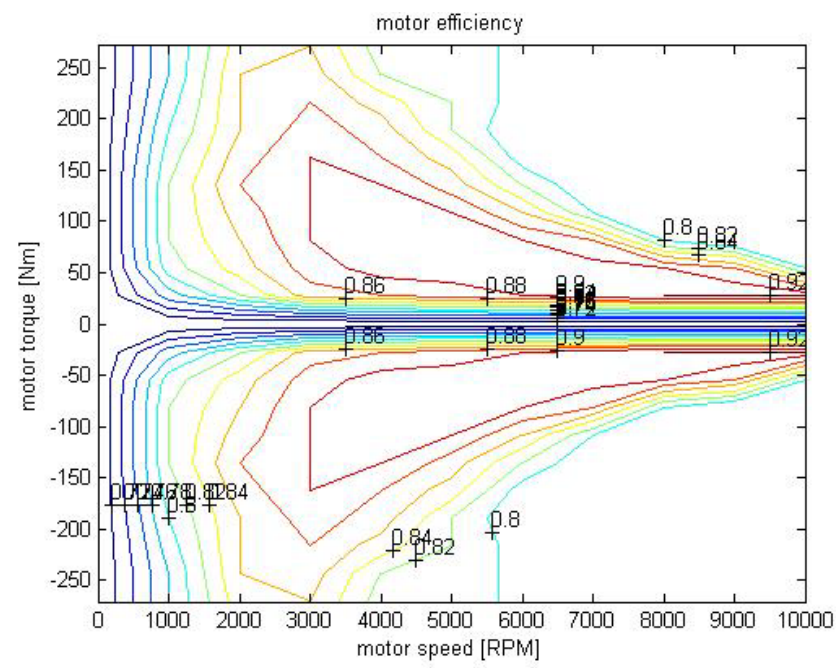

Figure 9. Contour of estimated Electric motor efficiency

\subsubsection{Generator model}

A $32 \mathrm{~kW}$ permanent magnet generator was used in this study, and the generator was substantially the same as electric motor model shown in Figure 10. 


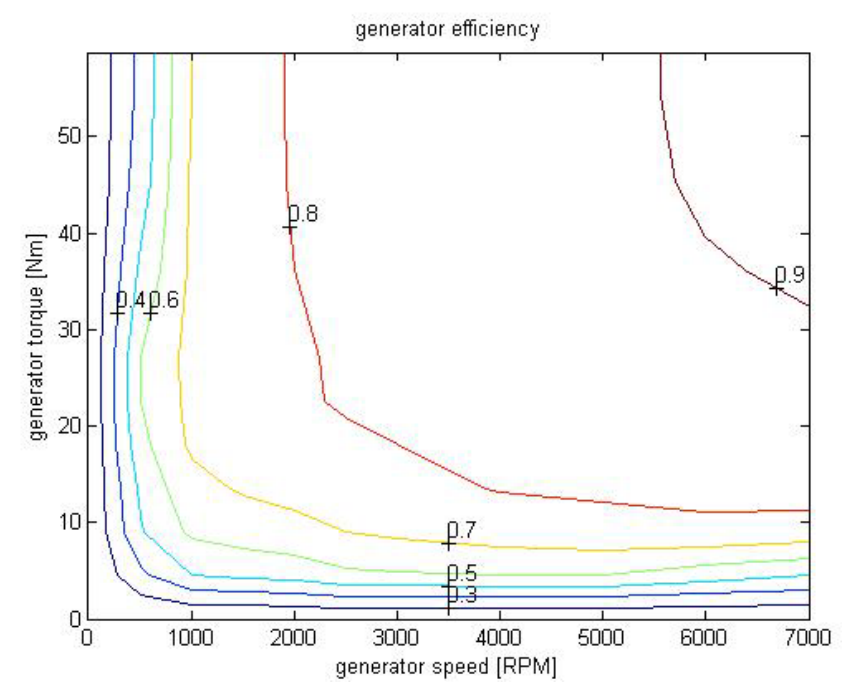

Figure 10. Contour of estimated Generator efficiency

\subsubsection{Hydraulic motor and hydraulic pump models}

Hydraulic motor and hydraulic pump models were used oblique axis piston hydraulic motor / pump in this study. And was applied reciprocating plunger in a limited volume movement, so after the inhalation of low pressure hydraulic fluid through the piston, and then compressed volume of high-pressure hydraulic oil would be discharged through the piston. The displacement in this process could be achieved by changing the angle of the swash plate to alter the pressure and flow, and thereby changing the relationship between torque and speed. The hydraulic motor / pump related formula was shown as following:

The fluid flow rate of Hydraulic motor / pump

$$
Q_{P / M}=x_{P / M} \omega_{P / M} D_{P / M}\left(\eta_{v P / M}\right)^{Z}
$$

The shaft torque Hydraulic motor / pump shaft torque

$$
T_{P / M}=x_{P / M} \Delta P_{P / M} D_{P / M}\left(\eta_{t P / M}\right)^{-Z}
$$

The shaft power of Hydraulic motor / pump shaft power

$$
P_{P / M}=x_{P / M} \Delta P_{P / M} D_{P / M} \omega_{P / M}\left(\eta_{t P / M}\right)^{-z}
$$

Where $Q_{P / M}$ was volume flow rate, $T_{P / M}$ was shaft torque, $P_{P / M}$ was axis function, $x_{P / M}$ was the volume ratio which was defined as the percentage displacement of $-1 \leq \mathrm{x} \leq$ 1 , as $\mathrm{x}$ was positive which was in the pump mode, and as $\mathrm{x}$ was negative which was in the motor mode, $\mathrm{x}$ was not zero for success., $D_{P / M}$ was the maximum volume displacement, $\omega_{P / M}$ was axis angular velocity, $\Delta \mathrm{P}_{P / M}$ was the pressure difference between the hydraulic motor / pump inlet and outlet, $\eta_{v P / M}$ was the was the volume loss efficiency, $\eta_{t P / M}$ was the mechanical loss efficiency, and $\mathrm{Z}$ was factor of working mode shown as following equation:

$$
\mathrm{Z}=\operatorname{sgn}(\mathrm{x})= \begin{cases}+1, & \text { pump mode } \\ -1, & \text { motor mode }\end{cases}
$$

The hydraulic motor / pump efficiency was the product of the total volumetric and mechanical efficiency, and usually affecting the operation efficiency was due to a variable (pressure difference and the volume flow rate), the hydraulic motor / pump parameters (volume displacement), and fluid parameters (fluid viscosity, density, volume modulus, etc.).

\subsection{HEV and HHV Control Strategies}

In order to investigate the HEV and HHV fuel economy, the study set the two control strategies to be the same. And in order to avoid often start engine, it will be set as SOC storage elements was less than 0.3 , and then the engine could be started again. Once started engine, SOC must charge storage element back to 0.9 before they can stop the engine. Optimum operating point of the engine speed control torque was set at $55 \mathrm{Nm}$ and $3500 \mathrm{rpm}$ to achieve the best fuel economy.

\section{Simulation Results and Discussion}

This section will explore a variety of architectures mentioned in Section 2, under the NEDC driving cycle and simulating the depletion of its energy state, the study obtained the performance comparison. And therefore to simulate the differences between HEV and HHV, the basic specifications of the vehicle could be unified as shown in Table 1.

Table 1. The common specifications of vehicles

\begin{tabular}{|c|c|c|c|}
\hline Parameter & symbol & value & unit \\
\hline Vehicle weight & $\mathrm{W}$ & 1500 & $\mathrm{~kg}$ \\
\hline $\begin{array}{c}\text { Rolling resistance } \\
\text { coefficient }\end{array}$ & $\mu_{r}$ & 0.008 & - \\
\hline $\begin{array}{c}\text { Air resistance } \\
\text { coefficient }\end{array}$ & $C_{D}$ & 0.28 & - \\
\hline $\begin{array}{c}\text { Vehicle orthographic } \\
\text { projection area }\end{array}$ & $A_{f}$ & 2.26 & $\mathrm{~m}^{2}$ \\
\hline Wheel radius & $\mathrm{r}$ & 0.315 & $\mathrm{~m}$ \\
\hline $\begin{array}{c}\text { Maximum vehicle } \\
\text { speed }\end{array}$ & $v_{F}$ & 180 & $\mathrm{~km} / \mathrm{hr}$ \\
\hline
\end{tabular}

\subsection{Hybrid Vehicle Simulation Results}

In order to clearly observe and understand the change of battery SOC, so that the NEDC driving patterns could be divided into two sets of simulations. Figure 11 represented the time response of the vehicle speed under the beginning of the first 2500 seconds interval. Figure 12 was shown the electric power level. Fig. 13 was the curve of the battery charge and discharge. Figure 14 was the generator actuated curve. Figure 15 was the battery SOC state. Apparently, the vehicle was started and used the battery as a drive source. As the battery SOC was used up to 0.3 , the engine started generating the electricity energy, and could be supplied to the battery while the electric motor was driven, and until the battery SOC reached 0.9 , the engine would be shut down. That would meet the original setting control strategies. 


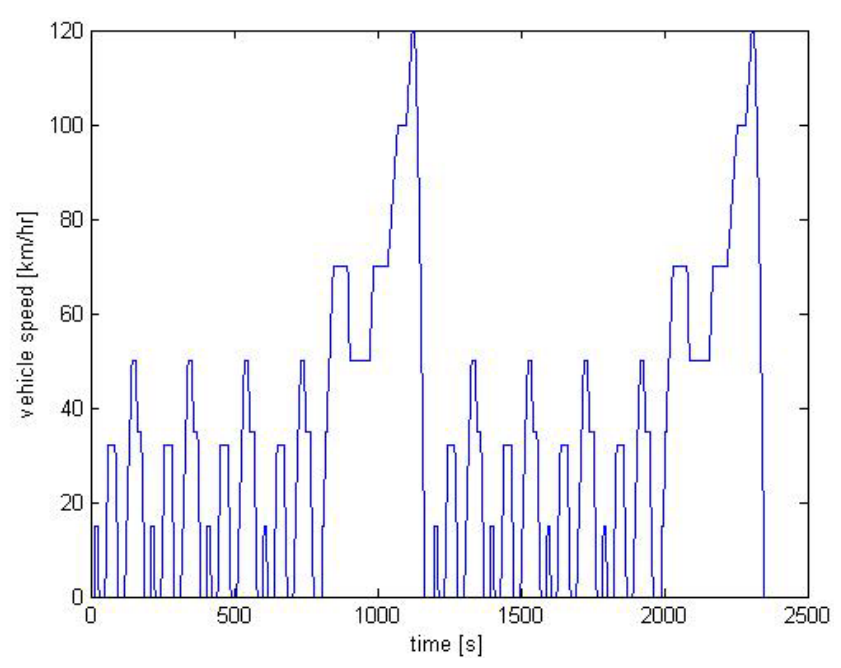

Figure 11. NEDC driving pattern(vehicle speed) curve during the first 2500 seconds.

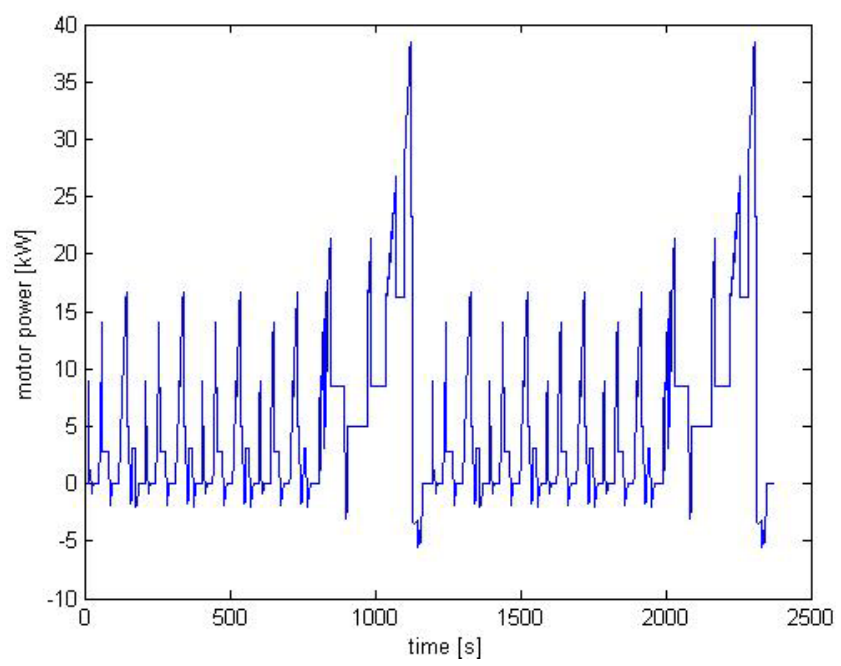

Figure 12. Eletric motor power curve during the first 2500 seconds.

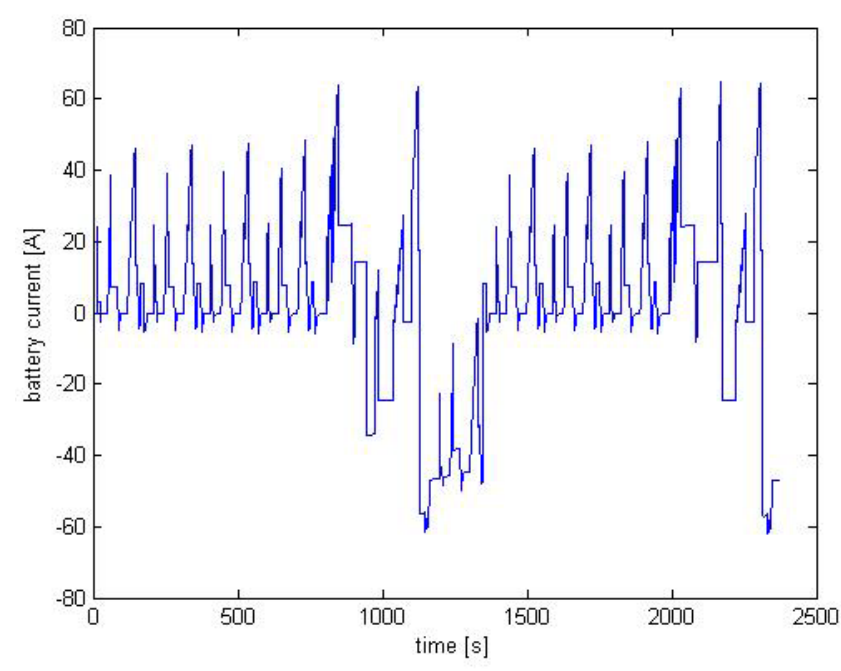

Figure 13. Battery current curve during the first 2500 seconds.

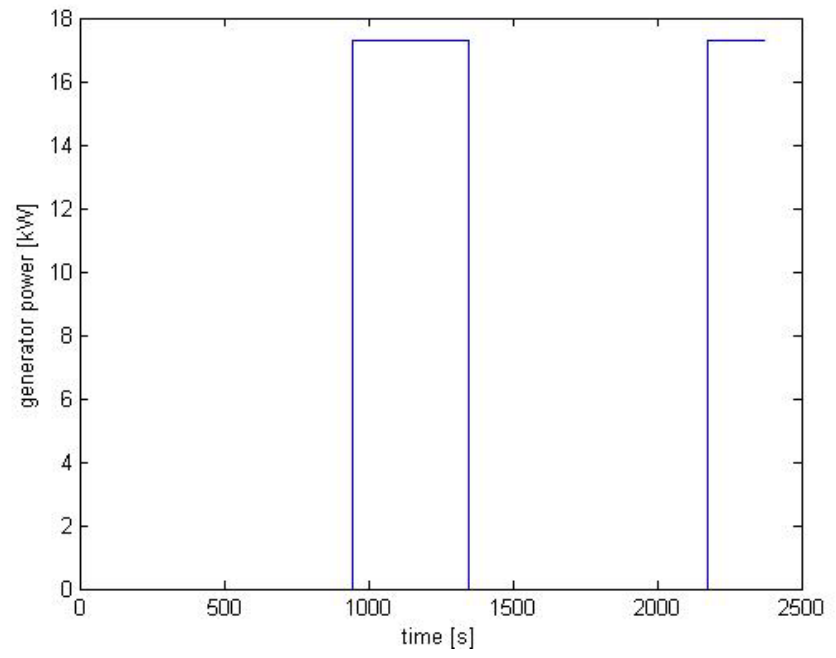

Figure 14. Generator power curve during the first 2500 seconds.

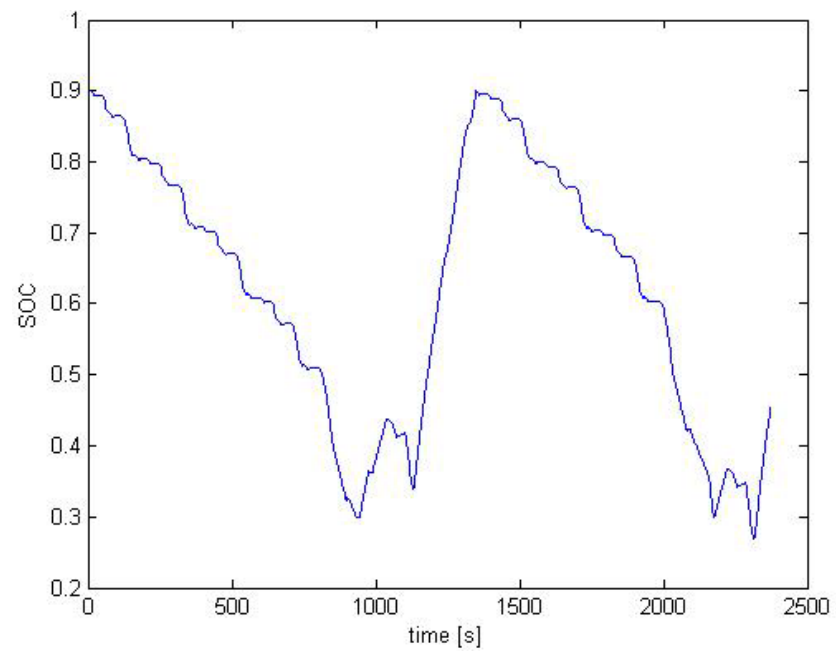

Figure 15. Battery SOC curve during the first 2500 seconds.

\subsection{Hydraulic Hybrid Vehicle Simulation Results}

In order to compare the simulation results with electric hybrid vehicles, the study also performed two sets of hydraulic hybrid vehicle NEDC driving patterns simulation program. The simulation results was shown in Fig, 16 which was a volume flow rate of the pressure accumulator curve, and the hydraulic pump(actuated pump )curve was shown in figure 17. Figure 18 was the related SOC state. From Figure 16 to 18 , which could be found that the number of starts (star-up) of hybrid car would be more frequently than the number of hydraulic hybrid car, and therefore from the study could affirm that the gasoline-electric hybrid-powered life will be shorter than the life of the hydraulic hybrid? From the simulation the actual fuel economy of hydraulic hybrid vehicles was savings $56.7 \%$ fuel consumption than Hybrid electric vehicle which was shown in Table 2 . The reason was caused by the accumulator, because the braking backfilled 
pronounced than the effect of a number of cells, the main difference was the physical change of the charge and discharge of hydraulic was simple, but the accumulator battery charging and discharging process was a chemical change which can vary significantly for greater chemical energy losses.

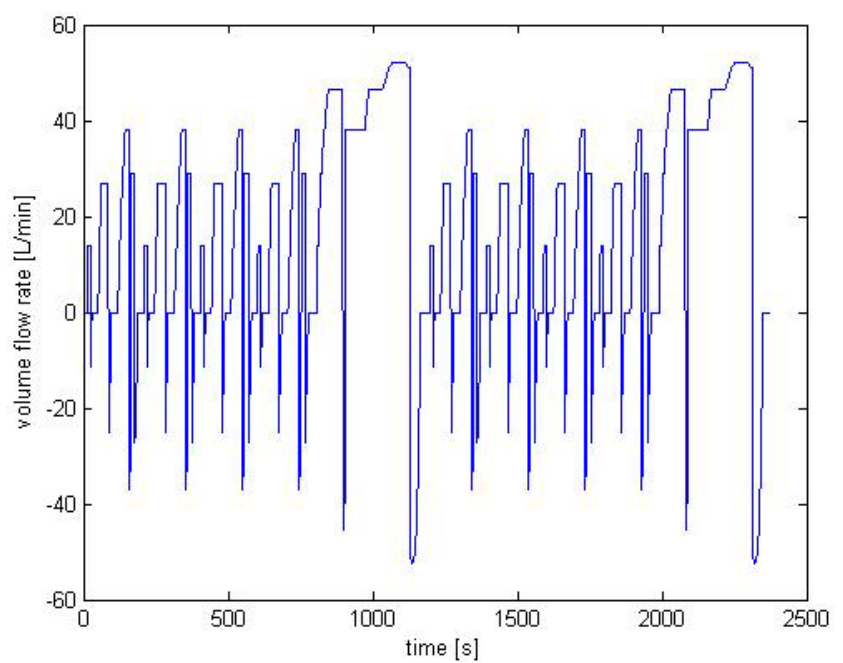

Figure 16. Accumulator volume flow rate during the first 2500 seconds

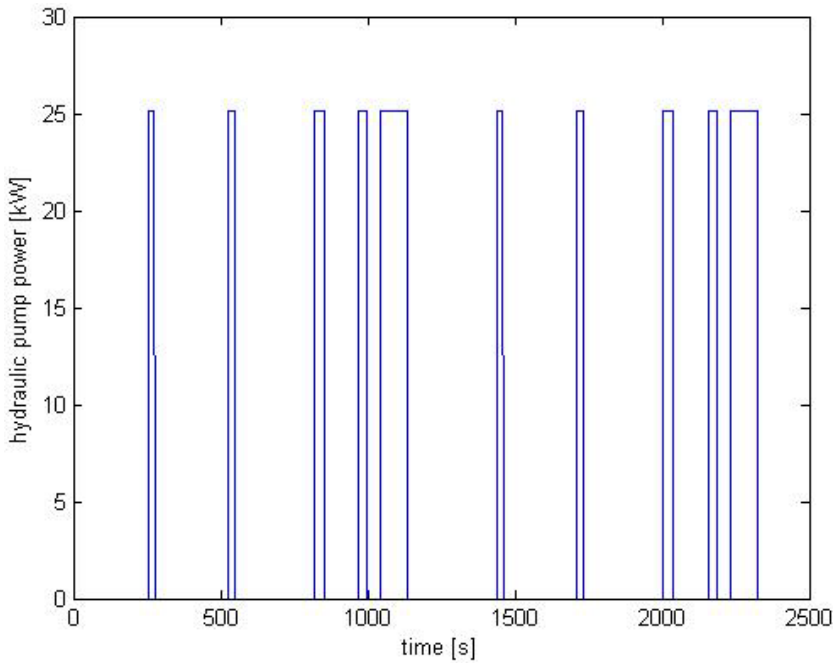

Figure 17. Hydraulic pumps actuation during the first 2500 seconds.

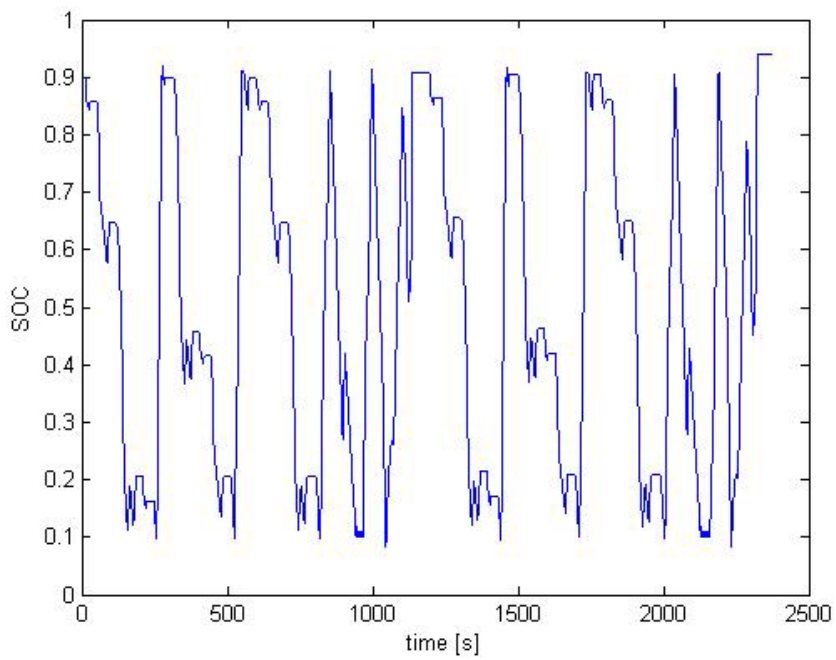

Figure 18. SOC state of the accumulator during the first 2500 seconds.
Table 2. The comparison of fuel economy for HEV and HHV.

\begin{tabular}{|c|c|c|}
\hline Category & HEV & HHV \\
\hline Fuel economy $(\mathrm{km} / \mathrm{L})$ & 15.82 & 24.79 \\
\hline
\end{tabular}

\section{Conclusions}

The study used European traffic patterns to simulate vehicle energy changes state, and could be clearly observed in the various components of the actuator status and efficiency in the system, that the hybrid vehicles and hydraulic hybrid fuel economy, energy storage SOC factors such elements could be known.

From simulation results that the pressure accumulator battery has a higher power density compared to the energy density of the hydraulic accumulator. The hydraulic accumulator was short, and should rely on the engine driving or braking kinetic energy stored in a hydraulic accumulator, which was more suitable for the stop-go urban driving patterns, and would actually be used in the vehicles, such as buses, garbage trucks, and so on.

Finally, the simulation results of this study with respect to the hydraulic hybrid vehicle hybrid vehicles could improve fuel economy up to $56.7 \%$. This was the significant contribution on this study.

\section{REFERENCES}

[1] GUO Xing home, Lu Huai smoked, Huang Shengming, gas hydraulic science, Gao Books Ltd, 2011.

[2] H. S. Dunn and P. H. Wojciechowski, "High-Pressure Hydraulic Hybrid with Regenerative Braking, " Proceeding of the 7th Intersociety Energy Conversion Engineering Conference, San Diego, CA, pp. 989-995, 1972.

[3] A. Pourmovahed, N. H. Beachley, and F. J. Fronczak, "Modeling of a Hydraulic Energy Regeneration System - Part I: Analytical Treatment," AEME Journal of Dynamic Systems, Measurement, and Control, pp.155-159, 1992.

[4] Parker's Hydraulic Hybrid Technologies, R. J. Marotta,2012,http://www.

wwcleancities.org/documents/HydraulicHybrid_Parker_Mar otta.pdf

[5] Factsheet HRB, Bosch Rexroth,2008. http://www.boschrexroth-us.com/country units/america/united states/en/Company/Press/trade show _information/a_downloads/Hydrostatic_Regenerative_Braki ng_Fact_Sheet.pdf

[6] Hydraulic Launch Assist The Eaton HLA System,Eaton, www.etopiamedia.net/ mtw/pdfs/EatonHLA1.ppt

[7] Hydrauliska hybrider -Vad händer , Parker, http://www.ifsfluid.se/Seminarium\% 20Hybriddrifter/Hydrauliska\%20hybrider\%202011-03-03\% 20Hybridseminarium\%20-\%20R\%20Werndin.pdf

[8] E. Tzirakis, et al., Vehicle Emissions and Driving Cycles: 
Comparison of The Athens Driving Cycle (ADC) With Ece-15 And European Driving, Cycle (EDC), Global NEST Journal, Vol 8, No 3, 2006 pp 282-290

[9] Baseley, S., et al., Hydraulic Hybrid Systems for Commercial Vehicles, SAE technical paper, 2007.

[10] Cheung Ka Ho, the use of reverse analog composite dynamic energy management motorcycles, Vehicle Engineering,
National Taipei University of Technology Master's thesis, Taipei, 2003.

[11] Yunus A. Cengel, Micheal A. Boles, Thermodynamics an Engineering Approach, McGrawHill, 2006.

[12] K. Petter, New system solutions for working hydraulics to achieve energy efficiency improvement, Presentation at IFS 2010 meeting, 27-28 January 2010, Norrköping, Sweden. 